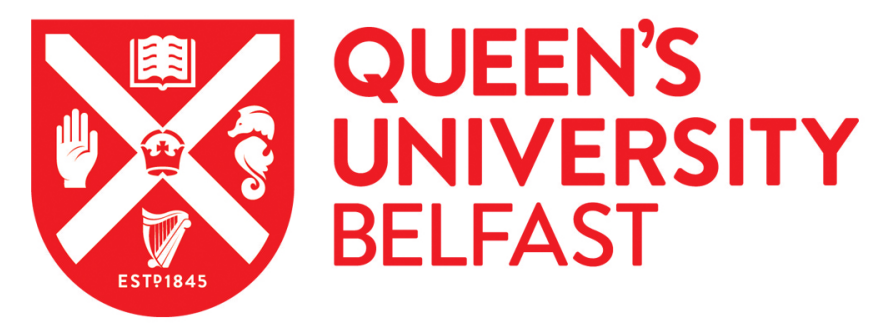

\title{
Traumatic brain injury and abuse among female offenders compared to non-incarcerated controls
}

O'Rourke, C., Linden, M. A., \& Lohan, M. (2018). Traumatic brain injury and abuse among female offenders compared to non-incarcerated controls. Brain Injury. https://doi.org/10.1080/02699052.2018.1539872

Published in:

Brain Injury

Document Version:

Peer reviewed version

Queen's University Belfast - Research Portal:

Link to publication record in Queen's University Belfast Research Portal

Publisher rights

Copyright (C) 2018 Informa UK Limited.

This work is made available online in accordance with the publisher's policies. Please refer to any applicable terms of use of the publisher.

\section{General rights}

Copyright for the publications made accessible via the Queen's University Belfast Research Portal is retained by the author(s) and / or other copyright owners and it is a condition of accessing these publications that users recognise and abide by the legal requirements associated with these rights.

Take down policy

The Research Portal is Queen's institutional repository that provides access to Queen's research output. Every effort has been made to ensure that content in the Research Portal does not infringe any person's rights, or applicable UK laws. If you discover content in the Research Portal that you believe breaches copyright or violates any law, please contact openaccess@qub.ac.uk. 
Title: Traumatic brain injury and abuse among female offenders compared to nonincarcerated controls.

\begin{abstract}
Objective: To examine the prevalence of traumatic brain injury (TBI) and past abuse experienced by adult female offenders.
\end{abstract}

Methods: Twenty-nine female offenders from a UK women's prison and twenty-nine age and gender matched university controls were recruited. In addition to demographic data, the Brain Injury Screening Index was utilized alongside the Childhood Trauma Questionnaire and the Abusive Behaviour Inventory.

Results: Approximately $79 \%(n=21)$ of female offenders reported a history of TBI, with $38 \%$ $(n=8)$ reporting six or more injuries. However, only $28.5 \%$ of female offenders reporting injury $(n=6)$ believed they had sustained a brain injury. Prevalence of both childhood $(n=$ $15,51.7 \%)$, and partner $(n=19,65.5 \%)$ abuse was also high among offenders. TBI Index scores correlated with past childhood and past partner physical abuse. Past mental illness, partner physical abuse, and number of convictions were predictive of greater TBI severity.

Conclusion: This is the first European study to examine combined TBI and abuse among an exclusively female offender population. It suggests that TBI is as prevalent among incarcerated females as it is among males. The unique presentation of female offenders must be acknowledged if effective rehabilitation programs are to be implemented.

Keywords: traumatic brain injury, prison, abuse, female offender, trauma 


\section{Introduction}

A growing body of work has developed around traumatic brain injury (TBI) within offender populations, with past meta-analyses consistently reporting high levels of TBI in both adult (1) and juvenile offenders (2). With the focus of such work primarily on male offenders, there is a dearth of available research surrounding female offenders with TBI (3-6). Of the nine prevalence studies identified (7-15) rates of TBI differed considerably, from $22.7 \%$ (11) to $100 \%$ (8). Among the limited research comparing TBI rates between male and female offenders, a number of studies have reported female offenders as having comparable, if not higher rates of injury then their male counterparts $(1,8,15,7)$. This finding is particularly important, given that the prevalence ratio of TBI among men and women in the general non-incarcerated population is approximately 2:1 (16).

The focus on male offenders within past research is most likely due to the underrepresentation of females in the criminal justice system (CJS). While female incarceration rates in the UK have remained relatively stable, showing a slow decrease over the past 10 years (17), females represent the fastest growing prison population in the US (18). Sex differences among both offenders and victims of crime are also particularly salient. While females generally represent a lower proportion of the victims of violent crimes, female offenders report much higher rates of intimate partner violence and child abuse than their male counterparts (17). The over-representation of female victims of violence and abuse in the CJS has been repeatedly acknowledged, with such emotionally traumatic experiences impacting upon subsequent alcohol and substance abuse, as well as overall adjustment to prison life $(19,20)$. As reported by the Ministry of Justice, drugs and alcohol may be used to "self-medicate" away memories of abuse which may resurface if a woman is not adequately 
supported in prison (20). For female offenders with residual psychological distress, poor adjustment can also represent a significant safety issue. While female offenders are less likely to experience assault in prison than men (195 vs 242 assaults per 1000 prisoners), they are much more likely to self-harm, and self-harm more frequently, than men (17).

Another possible reason for the under-representation of female offenders in the TBI literature is that TBIs among female offenders tend to be milder in severity (9), though the cause of injury is primarily violence against the person (9-11) as opposed to motor vehicle accidents for males (9). Jackson and colleagues (21) examined the prevalence and frequency of mild TBI (mTBI) among a sample of fifty-three women recruited from battered women's shelters and community outreach programs. While 92\% reported being struck on the head or face during partner violence, only $40 \%$ reported a loss of consciousness (LOC) from such injuries. Among those who reported any head injury, 91\% reported being struck in the past year, with a frequency of 2-5 times. While $95 \%$ of those who experienced any LOC reported symptoms consistent with post-concussive syndrome (PCS), the prevalence of PCS among those who had not experienced LOC was also high (68\%). As such, studies which include only TBIs with LOC may miss many of these milder injuries, particular those resulting from repeated prolonged partner abuse (21). Consideration of abuse as both a cause of injury and indicator of repeat injury is of particular importance within female offender samples. For example, Colantonio and colleagues (12) reported significantly higher rates of childhood physical and sexual abuse among female offenders with TBI compared to female offenders without $\mathrm{TBI}$, and male offenders overall.

TBI represents a significant, yet overlooked health concern among female offenders. Coupled with this, the role of TBI in both criminal offending and recidivism remains to be 
fully understood. A number of longitudinal and cohort studies have linked TBI to subsequent criminal behaviour (22-26). Additionally, several studies of offender populations have linked TBI to poorer executive functioning (27-29), aggression and violence $(8-10,7,30)$, anxiety and depression $(9,28,30,31)$, and an increased likelihood of repeat offending $(32,33)$. The overlap between such impairments and the factors considered to put a person at greater risk for criminality have been noted (34), though more work is needed to fully understand this relationship. The myriad of other factors, such as socio-economic status (SES), alcohol and substance abuse, and mental illness, which are often prevalent among offenders, would suggest that the relationship between TBI and offending is unlikely to be straightforward. McKinlay and Albicini (4) alluded to this point in their examination of the literature around TBI prevalence and associated mental health among individuals in the CJS. They emphasised that given the disparate TBI rates reported among offenders, coupled with the similarly high prevalence rates reported in some general population samples, the association between TBI and offending may be influenced by other social or economic factors.

The lack of available research surrounding female offenders with TBI is surprising, given the disproportionately high prevalence of injury within this group. Additionally, with sex differences noted in both criminal justice and TBI literature, there is a clear need to develop a better understanding of the differing needs presented by this group. The aim of this study is therefore to examine the prevalence of TBI and abuse among female offenders, and to examine the factors which contribute to more severe injury.

\section{Method}

Participants 
Recruitment of female offenders was conducted in two phases, April 2016 and July 2016, at a women's prison in the UK. The prison houses between 30-60 adult female offenders at any one time, with a combination of short and long-term sentences. No set inclusion criteria were used, though completion of the questionnaire required participants to understand and speak English. Of the 53 offenders approached, twenty-nine consented to participate (54.7\%). While attempts were made to recruit female offenders as controls, there was a marked lack of female offenders without reported TBI. Therefore, for the purposes of comparison, age-matched female controls were recruited from a university population $(n=29)$ between November 2016 and February 2017. Female controls were excluded if they had previously been incarcerated.

Instrumentation

Demographic information and criminal history including age, education, number of convictions, age at first offence, drug abuse, and alcohol abuse were collected. Current criminal convictions were dichotomized into violent (crimes against an individual e.g. assault, murder, robbery) and nonviolent (e.g. theft, drug possession, fraud, breach of bail) crimes. Maternal education was used as a proxy measure for socio-economic status, in line with previous research $(35,36)$. Reporting of a past mental health diagnoses or prescription of anti-depressant medication were used to record past mental illness. Two additional questions asked whether participants had ever been informed they had received a brain injury, or whether they thought they had a brain injury.

As it was not possible to access medical records, $\underline{T B I}$ screening was assessed by means of a modified version of the previously validated Brain Injury Screening Index (BISI) (28). This 7 item tool asks participants to report the number of times in which they have received a 
serious blow to the head that resulted in a loss of consciousness or where afterwards they felt very dazed and confused. Details on the length of LOC and post-injury care are also collected for up to five injuries. A score of between 0 and 3 is given for the length of LOC $(0=$ no LOC, $1=$ LOC less than 10 mins, $2=$ LOC between 10 mins and 6 hours, $3=$ LOC over 6 hours). Similarly, a score of between 0 and 6 is given for the number of injuries reported, with a score of 6 indicating participants experienced "more than five" injuries. In line with the guidelines of the original authors (28), this tool allowed for quantification of TBI Index scores by multiplying the highest rating for LOC (0-3) by the number of reported injuries (06). This produces a TBI Index score of 0-18 which can then be compared between participants. While alternative tools, such as the Ohio State University TBI Identification Method (OSU TBI-ID) (13) have been employed in similar populations, the BISI is the only known and validated tool that allows the production of TBI Index scores. Two additional sections recording age at injury and cause of injury were added in the modified version. When used with a sample of 613 adult offenders, the original tool showed a $95 \%$ accuracy rate in identifying TBI when compared with in depth structured clinical interview by a psychologist (28).

The Childhood Trauma Questionnaire- Short form (CTQ-SF) (37) is a 25-item self-report questionnaire assessing past experiences of maltreatment in childhood. It utilizes a five point Likert scale with 1 representing "Never True" and 5 representing "Very Often True". Subscales of physical abuse, emotional abuse, sexual abuse, emotional neglect, and physical neglect show good internal consistency (ranging from .81 to .95) and convergent validity with therapist ratings of past abuse (37). Responses to four items on the physical abuse subscale and five items on the sexual abuse sub-scale were dichotomized to give an overall prevalence of both physical and sexual abuse during childhood. 
The Abusive Behaviour Inventory (38) is a 30 -item self-report measure of past abusive behaviour perpetrated on women by their partners or former partners. Participants were asked to respond on a five point Likert Scale with 1 representing "Never" and 5 representing "Very Frequently". This measure shows good internal consistency (Chronbach's Aplha= .95) between the three subscales of physical abuse (.93), psychological abuse (.92), and sexual abuse (.85) (39). Again, responses to seven items on the physical abuse sub-scale and three items on the sexual abuse sub-scale were dichotomized to give an overall prevalence of both physical and sexual abuse during childhood.

Procedure

Participants were recruited through convenience sampling. Posters detailing the intentions of the research were distributed throughout the female offender wing. During this time, information sheets were also made available and offenders had the chance to ask questions about the research before agreeing to take part. Interested individuals provided their name and identification number which were forwarded to the bookings department to arrange an interview time.

Given the poor literacy levels of offenders, data were obtained in a face to face interview. This method was chosen to maximize the completion of questionnaire items and to aid with difficulties around terminology and question phrasing. Participants were taken to a quiet room and invited to read and complete the consent form and questionnaire at their own pace, or have the questions read aloud to them. Interview times ranged from 40-60 minutes and participants were offered regular breaks every 20 minutes.

An age-matched general population control group were drawn from a local university. Email invitations, which included a brief overview of the project alongside an information sheet 
explaining what the research involved, were circulated. Participants who were interested in taking part were asked to respond to the researcher detailing a suitable time to meet for testing. Testing lasted between $30-40$ minutes, with the researcher again offering to read the questions aloud in addition to answering any queries.

Ethics

Ethical approval was granted by an independent ethical review body. All participants were required to both read and indicate understanding of the information sheet before consenting to take part. Issues around confidentiality and withdrawal from research were included and verbally communicated before consent was obtained. Given the possible presence of brain injury, and the poor literacy levels of offenders, a second check regarding insight to consent was undertaken. This took the form of three questions, all of which needed to be answered correctly to constitute informed consent; What will I be talking to you about? Are there any bad things about talking to me? What should you do if you decide you do not wish to talk to me anymore?

Data analysis

Data analysis was conducted using SPSS version 22 (40). Demographic data were compared across all participants $(n=58)$ stratified by group. Differences in demographic, injury, and abuse data were examined using a combination of t-tests, Mann-Whitney $U$, and chisquared tests where appropriate. Spearman's rho was also conducted to explore the relationship between TBI Index scores and abuse measures, while a multiple linear regression examined the factors predictive of TBI Index scores. 


\section{Results}

The demographic and clinical characteristics of the 29 offenders and 29 controls are displayed in Table 1. Just under half of the offender sample had committed a violent crime $(48 \%, n=14)$, though no differences in reported TBI prevalence were observed between violent and non-violent offenders $X^{2}(1)=.013, p=.909$. Non-significant differences were found between offenders and controls in regard to age (Mann-Whitney $U=337, p=.190, r=$ .17), with significant differences found in terms of education, SES, past drug and alcohol use, and number and severity of TBI. Over half of offenders reported past drug abuse (55.2\%) or mental illness (69\%), with high rates of childhood physical abuse $(51.7 \%)$ and partner physical abuse (65.5\%). Reported partner physical abuse was also high among control females (31\%), as was mental illness (20.7\%). Furthermore, the control group were significantly younger at reported first injury than the offenders (Mann-Whitney $U=39, p=$ $.005, r=.5$ ), although offenders reported higher TBI Index scores overall (Mann-Whitney $U=$ $44, p=.009, r=.47)$.

Insert Table 1 here

History of TBI

Reported prevalence of TBI was 79.3\% $(n=21)$ in the offender group and $34 \%(n=10)$ among controls. When reported LOC was controlled, this dropped to $65.5 \%(n=19)$ and $31 \%(n=9)$ respectively. Though the majority of reported injuries were mild for both offenders $(n=11$; $52.4 \%)$ and controls ( $n=8 ; 80 \%)$, multiple injuries were more common among offenders, with $38 \%(n=8)$ reporting 6 or more injuries. Fifty-seven percent of female offenders also reported experiencing their first TBI prior to their first conviction. Participants were asked to report whether they believed they had a brain injury and whether they had ever been told 
they had a brain injury. Only 6 out of the 21 offenders reporting past TBI (28.5\%) reported believing they had sustained a brain injury, while none of the 10 controls believed so. Similarly, only four offenders and none of the controls reported being informed that they had sustained a brain injury. This is despite the fact that the majority of both offenders (61.9\%) and controls (80\%) reported attending hospital following their first injury. For subsequent injuries however, the majority of individuals reported doing "nothing" (second injury- 55.6\%; third injury - $64.3 \%$; fourth injury - 70\%; fifth Injury - $77.8 \%$ ). Of the total number of injuries recorded for both groups $(n=82)$, the main causes were falls $(31.7 \%)$, assault (30\%), and being struck with an object (28\%).

Prevalence of childhood and partner abuse

Reported prevalence of both childhood $(n=15 ; 51.7 \%)$ and partner $(n=19 ; 65.5 \%)$ physical abuse was high among female offenders. Table 2 shows the differences between offenders and controls both with and without reported TBI in terms of childhood and partner abuse. Scores were significantly higher for offenders who reported TBI than offenders who did not on measures of childhood emotional (Mann-Whitney $U=38.5, p=.025, r=.42$ ) and sexual abuse (Mann-Whitney $U=48, p=.032, r=.4$ ), as well as partner psychological (MannWhitney $U=31.5, p=.013, r=.47$ ), physical (Mann-Whitney $U=32, p=.014, r=.47$ ), and total abuse (Mann-Whitney $U=32, p=.014, r=.46$ ). However, the small number of offenders who did not report injury $(n=8)$ should be acknowledged when interpreting this finding. Scores were also significantly higher for offenders who reported TBI than controls who reported TBI on all abuse measures with the exception of both childhood and partner sexual abuse. Spearman's rho, conducted on all participants, indicated that TBI Index scores correlated 
with both childhood physical abuse $[r(58)=.374, p=.004]$ and partner physical abuse $[r(57)$ $=.581, p<.001]$.

Insert Table 2 here

Predictors of injury severity

We were also interested in examining the predictors of TBI Index scores among offenders $(n=29)$. Multiple linear regression was conducted to establish whether mental illness, childhood physical abuse, partner physical abuse, and number of convictions predicted TBI Index scores. The desired sample size $(n=40)$ was not reached for this analysis and findings should be interpreted with caution. Using the enter method the linear model was shown to be statistically significant $[F(4,22)=8.6, p<.001]$ with a multiple correlational coefficient of .78 , and approximately $61 \%$ of variation in TBI Index scores accounted for (Table 3). Mental illness $(t=2.52, p=.02)$, partner physical abuse $(t=3.28, p=.003)$, and number of convictions ( $t=3.33, p=.003)$ were significant predictors, however childhood physical abuse $(t=-1.97, p=$ .062) was not.

Insert Table 3 here

\section{Discussion}

Reported rates of TBI among female offenders (79\%) were over double that reported by female university students (34\%). While the majority of reported TBIs were mild for both offenders (52.4\%) and controls (80\%), 76\% of offenders reported experiencing more than one injury, with $38 \%$ reporting 6 or more injuries. Reported rates of childhood and partner abuse were also very high for offenders, with $51.7 \%$ reporting childhood physical abuse, and $65.5 \%$ reporting partner physical abuse. Among female university students, $20.7 \%$ reported 
past partner sexual abuse, and 31\% reported past partner physical abuse. Multiple regression analysis suggested that, $61 \%$ of variation in TBI Index scores could be accounted for by mental illness, number of convictions, partner physical abuse, and childhood physical abuse.

This study is part of a small but growing body of work examining TBI among adult female offenders. Considering the nine other prevalence studies identified, while Durand and colleagues (11) reported a much lower prevalence rate of $22.7 \%$, our rate of $79 \%$ is comparable to that of both Fishbein and colleagues (71.5\%) (7) and Ferguson and colleagues (72\%) (15) who utilized the Ohio State University TBI Identification Method (OSU-TBI-ID). It is also comparable to the prevalence rate of $69.98 \%$ reported following a meta-analysis of four studies of adult female prison populations (1). For over half of our offender sample (52.4\%) the most severe reported injury was mild, though 38\% reported experiencing 6 or more injuries. As noted by both Diamond and colleagues (9) and Ferguson and colleagues (15), there is a potential compounding effect of injuries, such that multiple mild TBIs can present with similar behavioural profiles as more severe injuries.

Reported prevalence of injury was also considerably high among our university control sample (34\%). Though rates again vary dramatically between studies, a recent meta-analysis estimated prevalence among females in the general population to be $8.55 \%$. Our prevalence rate is more closely matched to that of McKinlay and colleagues (41) who reported a TBI rate of $24.4 \%$ among females, using birth cohort data from the large Christchurch Health and Development Study (CHDS). The authors highlighted that use of self-report over alternative methods such as hospital records may have contributed to such high rates. Despite this prevalence, in contrast to the injury profile of offenders, the majority of 
reported injuries incurred by controls were single, mild events. While the exact cause has been disputed, it has been estimated that up to $15 \%$ of mild TBIs may result in persistent difficulties (42), meaning that our control sample were likely much less impaired than the offenders. Also, given that our control participants were well educated individuals, with high SES, they would be much more likely to seek help and support and had no experience with the CJS.

Particularly interesting were the differences in reported age at first injury between offenders and controls. Despite indicating significantly higher rates of childhood physical abuse, offenders reported a much older mean age (19 years) at first injury, relative to controls ( 8 years). There may be a number of reasons for this finding including the possibility that offenders simply could not recall injuries from childhood. Additionally, injuries experienced by offenders in childhood may have been overshadowed by other traumatic memories such as childhood abuse. Nonetheless, given the self-report nature of the current data, the small sample size, and the notable demographic differences between offenders and controls, it was not possible to investigate this finding in more depth and it should be interpreted with caution. Future research should however consider investigating the prevalence and recall of childhood TBIs among female offenders.

Of note within our sample was the lack of recognition that past TBIs had occurred. Only six of the twenty-one offenders with reported past TBI (28.5\%) and none of the nineteen control participants with reported past injuries believed they had experienced a TBI. This is despite $67 \%$ of participants attending hospital following their first injury. With research showing a lack of understanding around TBI among both the general public (43-46) and healthcare professionals $(47,48)$, this finding suggests that issues may exist around how TBI 
diagnoses are communicated to patients. Medical professionals, who themselves may lack knowledge of the possible long-term impact of mild and repeat injuries, are failing to adequately inform patients of both the presence of TBI and the potential behavioural, cognitive and social impacts that such injuries can have.

A history of abuse was highly prevalent among both offenders and controls, with TBI Index scores correlating with both childhood and partner physical abuse. Both childhood adversity and partner abuse have been shown to negatively impact a range of outcomes among female offenders, including mental health, rates of attempted suicide, and substance abuse (49-51). Mental illness, partner physical abuse, and number of convictions were all predictive of TBI Index scores, highlighting the complex vulnerability of this group. The exacerbating impact of such adverse life experiences on TBI requires further investigation, and raises significant questions regarding the directionality of the relationship between TBI and offending behaviour. Neuro-imaging of individuals with post-traumatic stress disorder (PTSD), which may occur following abuse, have shown decreased volumes of the hippocampus (52), amygdala, and frontal lobes (53), as well as disruption to white matter in the prefrontal cortex (54). This suggests that individuals who have experienced early adversity may be at a heightened vulnerability to the effects of TBI. While previous work with female offenders has largely focused on the relationship between TBI and violent behaviour $(5,10,14,55)$, greater investigation is needed to more broadly understand the complex interplay of TBI and adversity.

Limitations

Several limitations were evident while conducting this study. Firstly, despite an adequate participation rate $(54.7 \%)$ the sample size of female offenders was small, which limits the 
generalizability of our findings. In particular, the results of the multiple linear regression should be interpreted with caution as the desired number of participants for this analysis was not reached $(n=40)$. Additionally, self-selection bias may have also contributed to the reported prevalence of TBI within the sample. This may have adversely impacted the reliability and generalisability of the results. Future work among female offender populations should consider employing multi-centre research, or extending the period of data collection to allow for greater population turnover. Secondly, while the BISI has been shown to be a valid measure of TBI among prisoners, its reliance on self-report is not ideal. It is important to note that although individuals reported LOC and other symptoms suggestive of $\mathrm{TBI}$, independent verification was not possible as objective injury parameters were not available. Additionally, it is well known that self-report regarding medical conditions and hospitalisation becomes more unreliable over time and participants may have over or under estimated their injury severity. While it has been suggested that such tools may result in inflated rates of TBI (56), our use of a control group aimed to reduce this, showing that despite high rates reported in both groups, offenders still reported significantly more injuries, of a greater severity than controls. As few studies in the area include a control group, this is one of the strengths of our study. However, given the significantly higher educational attainment and SES of our controls, they were also not an ideal group for comparison. While the original aim was to recruit female offenders as controls, too few reported an absence of TBI to justify their use. Thirdly, the sensitive and personal nature of the questionnaire may have affected responses. Participants may have struggled to disclose past abuse, substance and alcohol misuse, and mental illness, with one participant unable to complete the $A B I$ despite indicating that abuse had occurred. Finally, the complexity of need evident within this population poses significant challenges to 
examining predictive relationships. Our study was primarily descriptive in focus, and further longitudinal work is required to tease apart the factors that contribute to the high prevalence of TBI among this group.

\section{Conclusions}

This study is the first of its kind in Europe to examine combined TBI and abuse among an exclusively female offender sample and adds to the small body of emerging literature showing significantly high rates of TBI among this group. The rate of reported TBI among female offenders (79\%) was over twice that found in the non-incarcerated control group $(34.5 \%)$ and is equivalent to the rates of TBI found amongst male offender samples.

These injuries also remained largely unrecognized by our sample, with only $28.5 \%$ of female offenders believing they had a TBI. This reflects the hidden nature of TBI among offenders, and reaffirms the need for additional screening upon entry to the CJS, alongside training for staff in its effects. In addition, only four offenders reported being told by a healthcare professional that they had a brain injury, despite $62 \%$ attending hospital following their first reported TBI. Greater consideration and training is needed around how healthcare professionals provide information to patients attending the emergency department for mTBI. Consideration should also be given to the adequacy of monitoring efforts to identify multiple mild injuries and possible instances of abuse.

Histories of abuse among offenders and controls raises significant questions around the prevalence and reporting of abuse resultant injuries within this group. Both childhood and partner physical abuse correlated with TBI Index scores, suggesting that abuse is a significant factor to consider in TBI research with females. Further work is needed not only 
to examine the reporting of such injuries, but to assess the impact and exacerbating effect such trauma may have on TBI outcomes.

With a predominant focus on male offenders within the literature, substantial work is needed to further our understanding of the sex differences associated with this condition. This applies especially to vulnerable populations, for which the effects of TBI are often most strongly felt. With rates equal to and greater than those reported by male offenders, TBI represents a significant health concern among female offenders, and greater consideration of this under-researched group is needed.

\section{Declaration of interest}

The authors have no interests to disclose.

\section{References}

1. Shiroma EJ, Ferguson PL, Pickelsimer EE. Prevalence of traumatic brain injury in an offender population: A meta-analysis. J Correct Health Care. 2010;16(2):147-59.

2. Farrer TJ, Frost RB, Hedges DW. Prevalence of traumatic brain injury in juvenile offenders: a meta-analysis. Child Neuropsychol. 2013;19(3):225-34.

3. O'Rourke C, Linden MA, Lohan M, Bates-Gaston J. Traumatic brain injury and cooccurring problems in prison populations: A systematic review. Brain Inj. 2016;30(7):839-54.

4. McKinlay A, Albicini M. Prevalence of traumatic brain injury and mental health 
problems among individuals within the criminal justice system. Concussion. 2016;1(4):CNC25.

5. O'Sullivan M, Glorney E, Sterr A, Oddy M, da Silva Ramos S. Traumatic brain injury and violent behavior in females: A systematic review. Aggress. Violent Behav. 2015;25:5464.

6. Durand E, Watier L, Lécu A, Fix M, Weiss JJ, Chevignard M, Pradat-Diehl P. Traumatic brain injury among female offenders in a prison population: results of the FleuryTBI study. Brain Behav. 2017;7(1).

7. Fishbein D, Dariotis JK, Ferguson PL, Pickelsimer EE. Relationships between traumatic brain injury and illicit drug use and their association with aggression in inmates. Int J Offender Ther Comp Criminol. 2016;60(5):575-97.

8. Slaughter B, Fann JR, Ehde D. Traumatic brain injury in a county jail population: prevalence, neuropsychological functioning and psychiatric disorders. Brain Inj. 2003;17(9):731-41

9. Diamond PM, Harzke AJ, Magaletta PR, Cummins AG, Frankowski R. Screening for traumatic brain injury in an offender sample: a first look at the reliability and validity of the Traumatic Brain Injury Questionnaire. J Head Trauma Rehabil. 2007;22(6):3308.

10. Brewer-Smyth K, Burgess AW, Shults J. Physical and sexual abuse, salivary cortisol, and neurologic correlates of violent criminal behavior in female prison inmates. Biol Psychiatry. 2004;55(1):21-31

11. Durand E, Watier L, Lécu A, Fix M, Weiss JJ, Chevignard M, Pradat-Diehl P. Traumatic 
brain injury among female offenders in a prison population: results of the FleuryTBI study. Brain Behav. 2017;7(1).

12. Colantonio A, Kim H, Allen S, Asbridge M, Petgrave J, Brochu S. Traumatic brain injury and early life experiences among men and women in a prison population. J Correct Health Care. 2014;20(4):271-9.

13. Bogner J, Corrigan JD. Reliability and predictive validity of the Ohio State University TBI identification method with prisoners. J Head Trauma Rehabil. 2009;24(4):279-91.

14. Shiroma EJ, Pickelsimer EE, Ferguson PL, Gebregziabher M, Lattimore PK, Nicholas JS, Dukes T, Hunt KJ. Association of medically attended traumatic brain injury and inprison behavioral infractions: A statewide longitudinal study. J Correct Health Care. 2010;16(4):273-86.

15. Ferguson PL, Pickelsimer EE, Corrigan JD, Bogner JA, Wald M. Prevalence of traumatic brain injury among prisoners in South Carolina. J Head Trauma Rehabil. 2012;27(3):E11-20.

16. Peeters W, van den Brande R, Polinder S, Brazinova A, Steyerberg EW, Lingsma HF, Maas Al. Epidemiology of traumatic brain injury in Europe. Acta neurochirurgica. 2015;157(10):1683-96.

17. Ministry of Justice. "Women and the criminal justice system statistics 2015." 2016. Retrieved from: https://www.gov.uk/government/uploads/system/uploads/attachment_data/file/57 2043/women-and-the-criminal-justice-system-statistics-2015.pdf

18. Swavola E, Riley K, Subramanian R. Overlooked: Women and jails in an era of reform. 
New York: Vera Institute of Justice; 2016.

19. Corston BJ. The Corston Report: A report of a review of women with particular vulnerabilities in the criminal justice system. Home Office; 2007.

20. Ministry of Justice. "A Distinct Approach : A guide to working with women offenders." 2012. Retrieved from; https://www.justice.gov.uk/downloads/publications/noms/2012/guide-workingwith-women-offenders.pdf

21. Jackson H, Philp E, Nuttall RL, Diller L. Traumatic brain injury: A hidden consequence for battered women. Prof Psychol Res Pr. 2002;33(1):39.

22. Elbogen EB, Wolfe JR, Cueva M, Sullivan C, Johnson J. Longitudinal predictors of criminal arrest after traumatic brain injury: Results from the traumatic brain injury model system National Database. J Head Trauma Rehabil. 2015;30(5):E3-13.

23. Timonen M, Miettunen J, Hakko H, Zitting P, Veijola J, von Wendt L, Räsänen P. The association of preceding traumatic brain injury with mental disorders, alcoholism and criminality: the Northern Finland 1966 Birth Cohort Study. Psychiatry Res. $2002 ; 113(3): 217-26$.

24. Fazel S, Lichtenstein P, Grann M, Långström N. Risk of violent crime in individuals with epilepsy and traumatic brain injury: a 35-year Swedish population study. PLoS med. 2011;8(12):e1001150.

25. Kennedy E, Heron J, Munafó M. Substance use, criminal behaviour and psychiatric symptoms following childhood traumatic brain injury: findings from the ALSPAC cohortEur Child Adolesc Psychiatry. 2017;1-0. 
26. McKinlay A, Corrigan J, Horwood U, Fergusson DM. Substance abuse and criminal activities following traumatic brain injury in childhood, adolescence, and early adulthood. J Head Trauma Rehabil. 2014;29(6):498-506.

27. Barnfield TV, Leathem JM. Neuropsychological outcomes of traumatic brain injury and substance abuse in a New Zealand prison population. Brain Inj. 1998;12(11):95162.

28. Pitman I, Haddlesey C, Ramos SD, Oddy M, Fortescue D. The association between neuropsychological performance and self-reported traumatic brain injury in a sample of adult male prisoners in the UK. Neuropsychol Rehabil. 2015;25(5):763-79.

29. Corrigan JD, Bogner J, Holloman C. Lifetime history of traumatic brain injury among persons with substance use disorders. Brain Inj. 2012;26(2):139-50.

30. Schofield PW, Butler TG, Hollis SJ, Smith NE, Lee SJ, Kelso WM. Neuropsychiatric correlates of traumatic brain injury (TBI) among Australian prison entrants. Brain Inj. 2006;20(13-14):1409-18.

31. Walker R, Hiller M, Staton M, Leukefeld CG. Head injury among drug abusers: an indicator of co-occurring problems. J Psychoactive Drugs. 2003;35(3):343-53.

32. Williams H, Cordan G, Mewse AJ, Tonks J, Burgess CN. Self-reported traumatic brain injury in male young offenders: a risk factor for re-offending, poor mental health and violence?. Neuropsychol Rehabil. 2010;20(6):801-12.

33. Ray B, Sapp D, Kincaid A. Traumatic brain injury among Indiana state prisoners. J Forensic Sci. 2014;59(5):1248-53.

34. Hughes N, Williams WH, Chitsabesan P, Walesby RC, Mounce LT, Clasby B. The 
prevalence of traumatic brain injury among young offenders in custody: a systematic review. J Head Trauma Rehabil. 2015;30(2):94-105.

35. Linden MA, Cepeda IL, Synnes A, Grunau RE. Stress in parents of children born very preterm is predicted by child externalising behaviour and parent coping at age 7 years. Arch. Dis. Child. 2015;archdischild-2014.

36. Grunau RE, Whitfield MF, Petrie-Thomas J, Synnes AR, Cepeda IL, Keidar A, Rogers M, MacKay M, Hubber-Richard P, Johannesen D. Neonatal pain, parenting stress and interaction, in relation to cognitive and motor development at 8 and 18 months in preterm infants. Pain. 2009;143(1):138-46.

37. Bernstein DP, Stein JA, Newcomb MD, Walker E, Pogge D, Ahluvalia T, Stokes J, Handelsman L, Medrano M, Desmond D, Zule W. Development and validation of a brief screening version of the Childhood Trauma Questionnaire. Child Abuse Negl. 2003;27(2):169-90.

38. Shepard MF, Campbell JA. The Abusive Behavior Inventory: A measure of psychological and physical abuse. J Interpers Violence. 1992;7(3):291-305.

39. Postmus JL, Stylianou AM, McMahon S. The abusive behavior inventory-Revised. J Interpers Violence. 2016;31(17):2867-88.

40. IBM Corp. IBM SPSS Statistics for Windows, Version 22.0. Armonk, NY: IBM Corp. Released 2013.

41. McKinlay A, Grace RC, Horwood LJ, Fergusson DM, Ridder EM, MacFarlane MR. Prevalence of traumatic brain injury among children, adolescents and young adults: prospective evidence from a birth cohort. Brain Inj. 2008;22(2):175-81. 
42. Bigler ED. Neuropsychology and clinical neuroscience of persistent post-concussive syndrome. J Int Neuropsychol Soc. 2008;14(1):1-22.

43. Gouvier WD, Prestholdt PH, Warner MS. A survey of common misconceptions about head injury and recovery. Arch Clin Neuropsychol. 1988;3(4):331-43.

44. Hux K, Schram CD, Goeken T. Misconceptions about brain injury: A survey replication study. Brain Inj. 2006;20(5):547-53.

45. Chapman RC, Hudson JM. Beliefs about brain injury in Britain. Brain Inj. 2010;24(6):797-801.

46. O’Jile JR, Ryan LM, Parks-Levy J, Gouvier WD, Betz B, Haptonstahl DE, Coon RC. Effects of head injury experience on head injury misconceptions. International Journal of Rehabilitation and Health. 1997;3(1):61-7.

47. Swift TL, Wilson SL. Misconceptions about brain injury among the general public and non-expert health professionals: an exploratory study. Brain Inj. 2001;15(2):149-65.

48. Yuhasz JE. Misconceptions about traumatic brain injury among correctional health care professionals. J Correct Health Care. 2013;19(2):135-43.

49. Friestad C, Åse-Bente R, Kjelsberg E. Adverse childhood experiences among women prisoners: relationships to suicide attempts and drug abuse. Int J Soc Psychiatry. 2014;60(1):40-6.

50. Tripodi SJ, Pettus-Davis C. Histories of childhood victimization and subsequent mental health problems, substance use, and sexual victimization for a sample of incarcerated women in the US. Int J Law Psychiatry. 2013;36(1):30-40. 
51. Minieri AM, Staton-Tindall M, Leukefeld C, Clarke JG, Surratt HL, Frisman LK. Relationship power as a mediator of intimate partner violence and mental health issues among incarcerated, substance-using women. Int J Offender Ther Comp Criminol. 2014;58(3):303-19.

52. Kasai K, Yamasue H, Gilbertson MW, Shenton ME, Rauch SL, Pitman RK. Evidence for acquired pregenual anterior cingulate gray matter loss from a twin study of combatrelated posttraumatic stress disorder. Biol Psychiatry. 2008;63(6):550-6.

53. Karl A, Schaefer M, Malta LS, Dörfel D, Rohleder N, Werner A. A meta-analysis of structural brain abnormalities in PTSD. Neurosci Biobehav. 2006; 30(7):1004-31.

54. Schuff N, Zhang Y, Zhan W, Lenoci M, Ching C, Boreta L, Mueller SG, Wang Z, Marmar CR, Weiner MW, Neylan TC. Patterns of altered cortical perfusion and diminished subcortical integrity in posttraumatic stress disorder: an MRI study. Neuroimage. 2011;54:S62-8.

55. Brewer-Smyth K, Burgess AW. Childhood sexual abuse by a family member, salivary cortisol, and homicidal behavior of female prison inmates. Nursing research. 2008;57(3):166-74.

56. McKinlay A, Corrigan JD, Bogner JA, Horwood L. Obtaining a History of Childhood Traumatic Brain Injury Using the Ohio State University TBI Identification Method to Elicit Adult Recall. J Head Trauma Rehabil. 2017. 
Table 1. Characteristics of participants by group

\begin{tabular}{|c|c|c|c|}
\hline & Offenders $(\mathrm{N}=29)$ & Controls $(\mathrm{N}=29)$ & $p$ \\
\hline Age, mean (SD) & $31.96(9.4)$ & $28.5(7.94)$ & .190 \\
\hline Number of Convictions, mean (SD) & $12.6(21.1)$ & - & \\
\hline Age at first conviction, mean (SD) & $23.5(11.5)$ & - & \\
\hline Violent offence $\mathrm{N}(\%)$ & $14(48)$ & - & \\
\hline TBI N (\%) & $21(72.4)$ & $10(34.5)$ & .004 \\
\hline Education N (\%) & & & $<.001$ \\
\hline Primary school & $11(37.9)$ & - & \\
\hline GCSE/equivalent* & $6(20.7)$ & - & \\
\hline Apprenticeship & - & $1(3.4)$ & \\
\hline Certificate/Diploma & $9(31)$ & $6(20.7)$ & \\
\hline A-Level/equivalent** & $3(10.3)$ & $10(34.5)$ & \\
\hline University Degree & - & $10(34.5)$ & \\
\hline Postgraduate Degree & - & $2(6.9)$ & \\
\hline Maternal Education (SES) N (\%) & & & .003 \\
\hline Primary school & $6(20.7)$ & $2(6.9)$ & \\
\hline GCSE/equivalent* & $6(20.7)$ & $5(17.2)$ & \\
\hline Apprenticeship & $1(3.4)$ & - & \\
\hline Certificate/Diploma & $4(13.8)$ & $5(17.2)$ & \\
\hline A-Level/equivalent** & $1(3.4)$ & $3(10.3)$ & \\
\hline University Degree & - & $9(31.9)$ & \\
\hline Postgraduate Degree & $1(3.4)$ & $1(3.4)$ & \\
\hline Unknown & $10(34.5)$ & $4(13.8)$ & \\
\hline Age at first TBI, mean (SD) & $19.3(9.5)$ & $8.2(6.7)$ & .005 \\
\hline
\end{tabular}




\begin{tabular}{|c|c|c|c|}
\hline TBI Index, mean (SD) & $4.44(5.38)$ & $0.48(.82)$ & .001 \\
\hline Number of TBI (\%) & & & $<.001$ \\
\hline 1 & $5(23.8)$ & $8(80)$ & \\
\hline 2 & $2(9.5)$ & $2(20)$ & \\
\hline 3 & 4 (19) & - & \\
\hline 4 & $1(4.8)$ & - & \\
\hline 5 & $1(4.8)$ & - & \\
\hline $6+$ & $8(38)$ & - & \\
\hline Most Severe Injury N (\%) & & & .278 \\
\hline No LOC & $2(9.5)$ & $1(10)$ & \\
\hline LOC $<10$ mins & $9(42.9)$ & $7(70)$ & \\
\hline LOC $<6$ hours & $8(38.1)$ & $1(10)$ & \\
\hline LOC $>6$ hours & $2(9.5)$ & $1(10)$ & \\
\hline Drug Abuse N (\%) & $16(55.2)$ & $1(3.4)$ & $<.001$ \\
\hline Alcohol Abuse N (\%) & $13(44.8)$ & $1(3.4)$ & $<.001$ \\
\hline Mental Illness N (\%) & $20(69)$ & $6(20.7)$ & $<.001$ \\
\hline Childhood Physical Abuse N (\%) & $15(51.7)$ & $2(6.9)$ & $<.001$ \\
\hline Partner Physical Abuse N (\%) & $19(65.5)$ & $9(31)$ & .009 \\
\hline Childhood Sexual Abuse N (\%) & $8(27.6)$ & $2(6.9)$ & .039 \\
\hline Partner Sexual Abuse N (\%) & $14(48.3)$ & $6(20.7)$ & .028 \\
\hline
\end{tabular}

*GCSE is a school qualification offered in the United Kingdom to students aged between 14-16 years. **A-Level or Advanced level is a school qualification offered in the United Kingdom to students aged between $16-18$ years 
Table 2. Differences and mean scores for childhood and partner abuse.

\begin{tabular}{|c|c|c|c|c|c|c|c|}
\hline & \multicolumn{2}{|c|}{ Offenders $(\mathrm{N}=29)$} & \multirow[t]{2}{*}{$p$} & \multicolumn{2}{|c|}{ Controls $(\mathrm{N}=29)$} & \multirow[t]{2}{*}{$p$} & \multirow[t]{2}{*}{$p^{*}$} \\
\hline & TBI & Non-TBI & & TBI & Non-TBI & & \\
\hline \multicolumn{8}{|l|}{ Childhood Trauma } \\
\hline Total & 58.05 & 37.63 & .117 & 29 & 33.89 & .925 & .002 \\
\hline Physical Abuse & 10.62 & 7.25 & .076 & 5.3 & 5.79 & .834 & .004 \\
\hline Emotional Abuse & 14.29 & 8 & .025 & 6.7 & 7.32 & .681 & .005 \\
\hline Sexual Abuse & 10.95 & 5 & .032 & 5 & 6.37 & .296 & .059 \\
\hline Emotional Neglect & 12.1 & 10.25 & .623 & 5.7 & 7.79 & .351 & .008 \\
\hline Physical Neglect & 10.1 & 7.13 & .178 & 6.3 & 6.63 & .776 & .048 \\
\hline \multicolumn{8}{|l|}{ Partner Abuse } \\
\hline Total & 75.9 & 41.13 & .014 & 42.5 & 38.68 & .158 & .013 \\
\hline Physical Abuse & 26.25 & 14.13 & .014 & 14.1 & 12.84 & .138 & .008 \\
\hline Psychological Abuse & 42.3 & 22.38 & .013 & 24.8 & 21.63 & .187 & .015 \\
\hline Sexual Abuse & 7.35 & 4.63 & .135 & 3.6 & 4.21 & .669 & .061 \\
\hline
\end{tabular}

$\mathrm{p}^{*}$ - Mean differences between offenders with TBI and controls with TBI. 
Published in Brain Injury 30/10/2018 available from

https://www.tandfonline.com/doi/full/10.1080/02699052.2018.1539872

Table 3. Summary of multiple linear regression for variables predictive of TBI Index scores $(n=29)$

\begin{tabular}{|l|c|c|c|}
\hline \multicolumn{1}{|c|}{ Variable } & B & SE B & $\beta$ \\
\hline Constant & -1.894 & 1.76 & \\
\hline Partner Physical Abuse & .213 & .065 & $.512^{* *}$ \\
\hline Childhood Physical Abuse & -.303 & .154 & -.320 \\
\hline Number of Convictions & .115 & .035 &. $\mathbf{4 5 8 * *}$ \\
\hline Mental Illness & 3.933 & 1.562 & $.351^{*}$ \\
\hline $\mathrm{R}^{2}=.61$ & & & \\
\hline $\mathrm{F}=\mathbf{8 . 6 0 2 * * *}$ & & & \\
\hline
\end{tabular}

${ }^{*} \mathrm{p}<.05,{ }^{* *} \mathrm{p}<.01, * * * \mathrm{p}<.001$ 